\title{
STRATEGI PENINGKATAN KINERJA SUPPLY CHAIN BUAH NAGA DI KECAMATAN BANGOREJO KABUPATEN BANYUWANGI BERDASARKAN PROSES INTI SCOR
}

Oleh :

\author{
KANTHI PANGESTUNING PRAPTI *), RIDWAN ISKANDAR dan KASUTJIANINGATI **)
}

\begin{abstract}
ABSTRAK
Kabupaten Banyuwangi merupakan salah satu daerah di Propinsi Jawa Timur yang menjadi sentra produksi buah naga dan Kecamatan Bangorejo menyumbang 39\% dari total produksi buah naga di Banyuwangi atau setara 11.000 ton per ha dengan luas lahan mencapai 449 ha. Jumlah produksi buah naga di Kabupaten Banyuwangi pada setiap musim menunjukkan nilai yang tidak sama. Kontinuitas komoditi buah naga dapat menghambat supply chain di dalam agribisnis buah naga baik di dalam negeri dan maupun tujuan ekspor.Penelitian ini dilakukan untuk mendapatkan strategi peningkatan kinerja supply chain buah naga berdasarkan proses inti Supply Chain Operations Reference (SCOR) dan pengolahan data menggunakan Objective Matrix (OMAX). Hasil penelitian diperoleh nilai indeks performansi supply chain sebesar 5,987. Berdasarkan Traffic Light System nilai tersebut termasuk dalam kategori kuning yang menunjukkan bahwa masih perlu adanya perbaikan terhadap kinerja supply chain buah naga yang ada di Kecamatan Bangorejo Kabupaten Banyuwangi.
\end{abstract}

Kata kunci : Strategi Peningkatan Kinerja, Supply Chain, SCOR, OMAX, Traffic Light System

\section{PENDAHULUAN}

Buah naga (Hylocereus) merupakan buah yang mempunyai nilai ekonomi tinggi dan prospek yang baik untuk dibudidayakan di Indonesia. Iklim tropis dengan intensitas cahaya matahari yang cukup baik memungkinkan buah naga dapat berbuah sepanjang tahun. Berdasarkan hasil penelitian, ternyata buah ini banyak memiliki khasiat seperti menguatkan fungsi ginjal, meningkatkan ketajaman mata, menstabilkan kadar gula darah, menguraikan kolesterol, keputihan dan sebagai anti oksidan (Paull, 2002).

Pusat produksi buah naga di Indonesia berada Propinsi Kalimantan Timur dan Jawa Timur. Kabupaten Banyuwangi merupakan salah satu daerah di Propinsi Jawa Timur yang menjadi sentra produksi buah naga (Beritasatu.com, 2014). Data dari Dinas Pertanian Kabupaten Banyuwangi menunjukkan bahwa sentra produksi buah naga di Kabupaten Banyuwangi berada di Kecamatan Bangorejo, Purwoharjo, Pesanggaran, Gambiran, Cluring, dan Sempu. Bangorejo menyumbang 39\% dari total produksi buah naga di Banyuwangi atau setara 11.000 ton per ha dengan luas lahan mencapai 449 ha.

Jumlah produksi buah naga di Kabupaten Banyuwangi pada setiap musim menunjukkan nilai yang tidak sama. Kontinuitas komoditi buah naga dapat menghambat supply chain di dalam agribisnis buah naga baik di dalam negeri dan maupun tujuan ekspor. Pengukuran kinerja supply chain perusahaan, dapat dilakukan dengan pendekatan Supply Chain Operation Reference (SCOR) yang mengukur performansi perusahaan berdasarkan lima proses inti yaitu plan, source, make, deliver, dan return. Setelah didefinisikan metrik-metrik SCOR yang sesuai dengan perusahaan dan didapatkan nilai performa, maka selanjutnya dilakukan benchmark antara hasil pengukuran performa dengan target yang diharapkan dengan menggunakan Objective Matrix (OMAX).

\section{METODE PENELITIAN}

Metode analisis data yang digunakan pada penelitian ini antara lain :

1. Analisis potensi agribisnis buah naga di Kecamatan Bangorejo kabupaten Banyuwangi menggunakan metode studi lapang dan studi pustaka.

2. Kondisi umum dan model rantai pasok dianalisis dengan mengunakan metode deskriptif-kualitatif, berdasarkan data kuantitatif-numerik dan kualitatif, dengan memperhatikan pendapat pakar dan nara sumber.

3. SCOR digunakan untuk menentukan metrik kinerja dan penentuan bobot metrik pengukuran kinerja supply chain.

4. OMAX digunakan untuk menentukan kriteria kinerja yang dapat digunakan sebagai ukuran produktivitas sehingga dapat digunakan untuk 
Kanthi Pangestuning P, Ridwan Iskandar dan Kasutjianingati, Strategi Peningkatan Kinerja SUPPLY

CHAIN Buah Naga Di Kecamatan Bangorejo Kabupaten Banyuwangi Berdasarkan Proses Inti Scor

merumuskan strategi kinerja supply chain buah naga.

5. Root Cause Analysis digunakan untuk menemukan akar permasalahan dan mencari solusi yang tepat untuk perbaikan.

\section{HASIL DAN PEMBAHASAN}

\section{Indentifikasi Supply Chain Buah Naga}

Gambaran umum kegiatan supply chain buah naga di Kecamatan Bangorejo Kabupaten Banyuwangi sebagaimana terlihat pada Gambar 1.

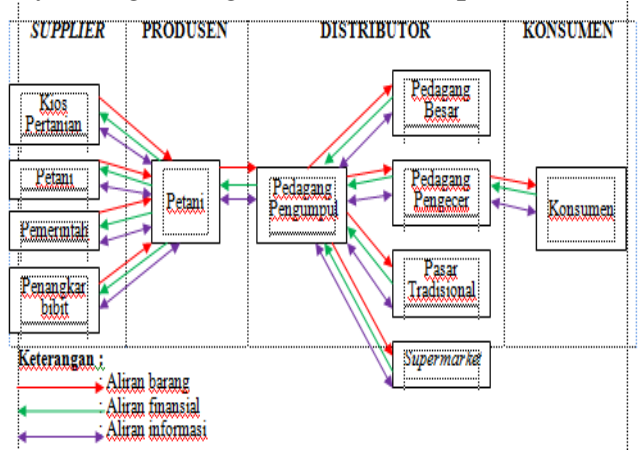

Gambar 1. Aliran Aktivitas Supply Chain Buah Naga Kecamatan Bangorejo Kabupaten Banyuwangi

\section{Klasifikasi Aktivitas Supply Chain berdasarkan Model SCOR}

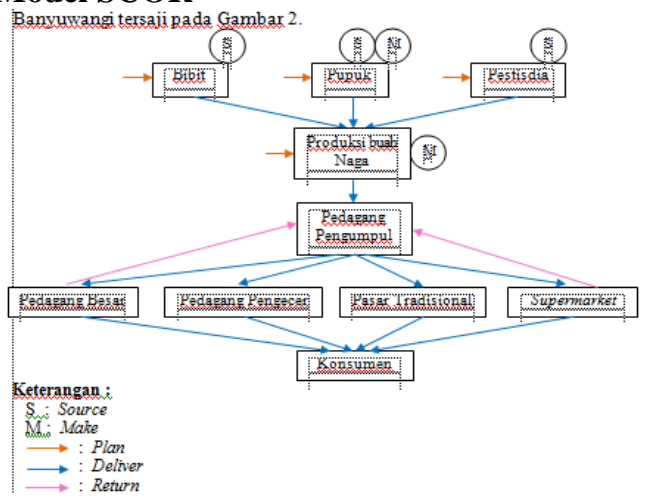

\section{Gambar 2. Klasifikasi Aktifitas Supply Chain Buah Naga Bangorejo}

\section{Pengukuran Performansi Supply Chain}

Pengukuran performansi pada SCOR menggunakan lima prespektif sebagai proses inti. Masing-masing perspektif yang digunakan, terdiri dari beberapa KPI (Key Performance Indicator). Adapun KPI masing-masing perspektif dapat dilihat pada Tabel 1.

Tabel 1. Kode dan KPI pada setiap Perspektif

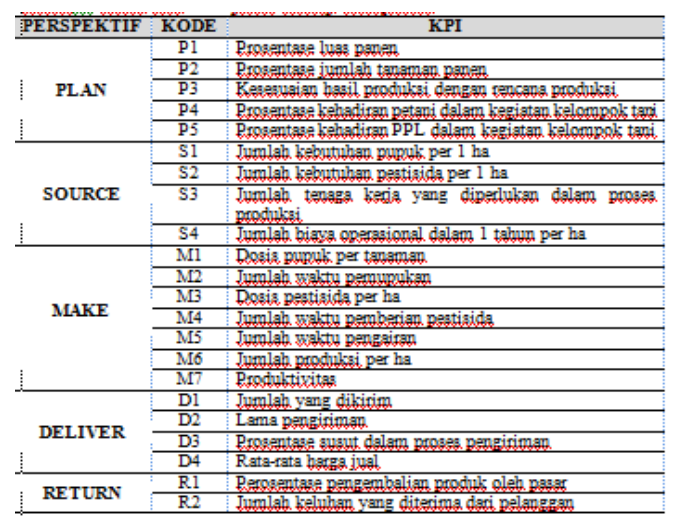

Tabel 2. Hasil Pembobotan Perspektif dan KPI

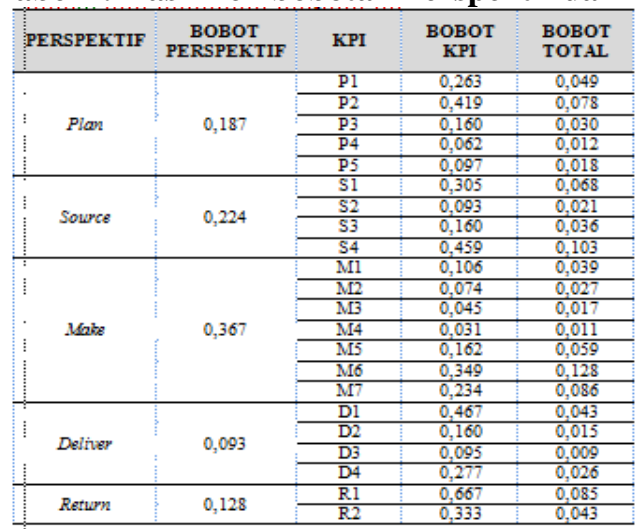

Scoring System

Scoring system dilakukan menggunakan Objective Matrix (OMAX) dan dilanjutkan dengan menggunakan Traffic Light System (TLS). Indikator Traffic Light System direpresentasikan dengan tiga warna yaitu hijau, kuning, dan merah.

Warna hijau merupakan pencapaian indikator kinerja sudah tercapai bahkan melampaui target yang ditetapkan. Warna kuning merupakan pencapaian dari suatu indikator kinerja yang belum tercapai sehingga masih harus diperbaiki. Warna merah merupakan pencapaian dari suatu indikator kinerja yang berada di bawah target yang tealh ditetapkan dan segera memerlukan perbaikan. Hasil pengukuran performansi supply chain masingmasing perspektif SCOR pada supply chain buah naga di Kecamatan Bangorejo Kabupaten Banyuwangi dapat dilihat pada Tabel 3 sampai dengan Tabel 8.

Tabel 3. Pengukuran Performansi Supply Chain Perspektif Plan 


\begin{tabular}{|c|c|c|c|c|c|}
\hline KPI & P1 & P2 & P3 & P4 & P5 \\
\hline Performance & 7,70 & 7,71 & 104,11 & 72,50 & 20,00 \\
\hline 10 & 16,72 & 16,80 & 105,14 & 75,71 & 29,98 \\
\hline $\mathbf{1 0}$ & 15,51 & 15,58 & 104,40 & 74,26 & 27,90 \\
\hline $\mathbf{8}$ & 14,30 & 14,36 & 103,66 & 72,81 & 25,82 \\
\hline $\mathbf{7}$ & 13,09 & 13,14 & 102,92 & 71,36 & 23,74 \\
\hline $\mathbf{6}$ & 11,88 & 11,92 & 102,18 & 69,91 & 21,66 \\
\hline $\mathbf{5}$ & 10,67 & 10,70 & 101,44 & 68,46 & 19,58 \\
\hline $\mathbf{4}$ & 9,46 & 9,48 & 100,70 & 67,01 & 17,50 \\
\hline $\mathbf{3}$ & 8,25 & 8,26 & 99,96 & 65,56 & 15,42 \\
\hline 2 & 6,16 & 6,15 & 97,40 & 62,04 & 13,62 \\
\hline 1 & 4,07 & 4,05 & 94,85 & 58,52 & 11,81 \\
\hline 0 & 1,98 & 1,95 & 92,30 & 55,00 & 10,00 \\
\hline Lerel & 2,73 & 2,74 & 8,61 & 7,79 & 5,20 \\
\hline Weight & 0,263 & 0,419 & 0,160 & 0,062 & 0,097 \\
\hline Value & 0,718 & 1,148 & 1,378 & 0,483 & 0,504 \\
\hline Plan & & & 4,231 & & \\
\hline
\end{tabular}

Tabel 4. Pengukuran Performansi Supply Chain Perspektif Source

$$
\begin{aligned}
& \text { \$2 Iabel 4. Penzukuran Performansi Suyply Chain PerspeltiffSow }
\end{aligned}
$$

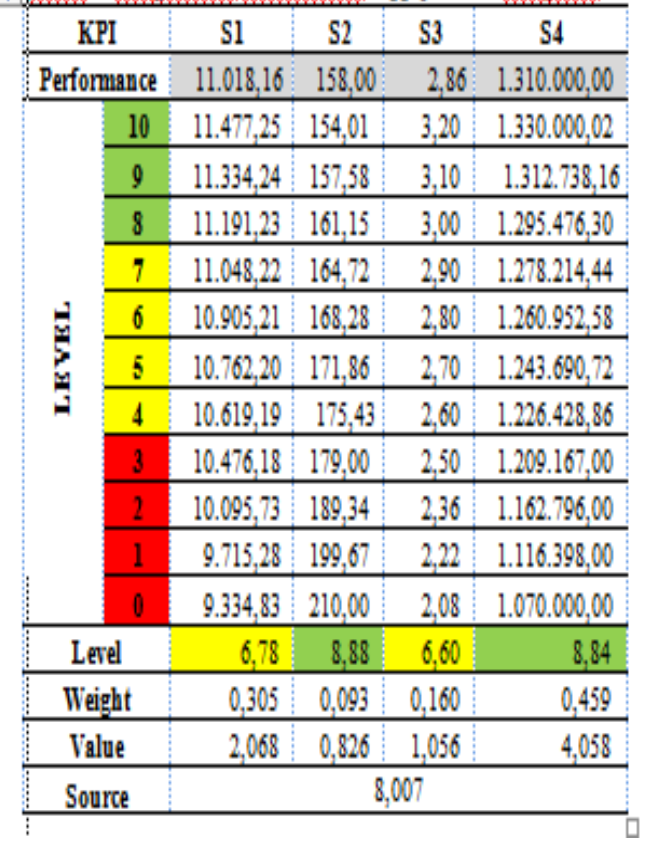

Tabel 5. Pengukuran Performansi Supply Chain Perspektif Make

\begin{tabular}{|c|c|c|c|c|c|c|c|}
\hline \multicolumn{8}{|c|}{ 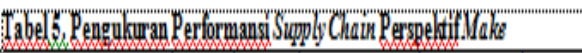 } \\
\hline KPI & MI & II & $\mathbb{D B}$ & IIH & $\sqrt{16}$ & 1.16 & .177 \\
\hline Performance & 1,440 & 1,580 & 0,207 & 0,610 & 0,540 & $14,703,12$ & 0,113 \\
\hline \multirow{11}{*}{ 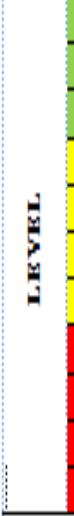 } & 1,502 & 1,022 & 0,206 & 0,613 & 0,717 & $15,620,22$ & 0,593 \\
\hline & 1,483 & 1,589 & 0,210 & 0,648 & 0,616 & $15.482,22$ & 0,283 \\
\hline & 1.464 & 1,556 & 0,214 & 0,683 & 0,515 & $15.344,22$ & 0,252 \\
\hline & 1,445 & 1,523 & 0,218 & 0,718 & 6,414: & $15.200,22$ & 0,221 \\
\hline & 1,426 & 1,490 & 0,222 & 0,753 & 0,313 & $15.068,22$ & 0,190 \\
\hline & 1,407 & 1,457 & 0,226 & 0,788 & 0,212 & $14,030,22$ & 0,159 \\
\hline & 1,388 & 1,424 & 0,230 & 0,823 & 0,111 & $14,792,22$ & 0,141 \\
\hline & 1.360 & 1,391 & 0.234 & 0,858 & 6,010 & $14.654,22$ & 0,123 \\
\hline & 1,320 & 1,320 & 0,246 & 0,932 & 5,600 & $14,296,58$ & 0,091 \\
\hline & 1,270 & 1,260 & 0,257 & 1,006 & 5,370 & $139.988,94$ & 0,000 \\
\hline & 1,220 & 1,210 & 0,268 & 1,080 & 5,050 & $13,581,30$ & 0,029 \\
\hline Lerel & 6,73 & 8,73 & 9,75 & 10,00 & 8,25 & 3,39 & 2,69 \\
\hline Weight & 0,106 & 0,074 & 0,045 & 0,031 & 0,162 & 0,349 & 0,234 \\
\hline Value & 0,713 & 0,046 & 0,439 & 0,310 & 1,337 & 1,169 & 0,629 \\
\hline \ake & & & & 5.243 & & & \\
\hline
\end{tabular}

Tabel 6. Pengukuran Performansi Supply Chain Perspektif Deliver

\begin{tabular}{|c|c|c|c|c|c|}
\hline & PI & $\mathrm{Dl}$ & D2 & D3: & D4 \\
\hline \multicolumn{2}{|c|}{ Perfonmance } & 450,00 & 14,360 & 5,50 & $17.500,00$ \\
\hline \multirow{11}{*}{ 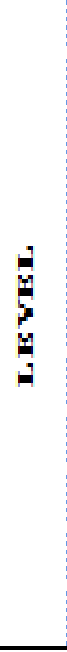 } & 10 & 9,01 & 14,238 & 5,104 & $2,0,02$ \\
\hline & 9 & 843,2 & 14,314 & 5,371 & $20.785,74$ \\
\hline & 8 & 787,03 & 14,390 & 5,688 & 19.571 .45 \\
\hline & 1 & 730,54 & 14,466 & 5,95 & $18.357,16$ \\
\hline & 6 & 674,05 & 14,542 & 6,17 & $17.42,87$ \\
\hline & 5 & 617,56 & 14,618 & 6,439 & $15,928,58$ \\
\hline & 4 & 561,07 & 14,694 & 6,606 & $14,714,20$ \\
\hline & & 504,58 & 14,77 & 6,873 & $13.500,00$ \\
\hline & & 409,72 & 14,980 & 7,501 & $11,00,00$ \\
\hline & & 314,86 & 15,900 & 8210 & $8.50,0$ \\
\hline & & 20,0 & 15,400 & 9,00 & $6,0,0$ \\
\hline Let & & 2,42 & 861 & 8,48 & 6,29 \\
\hline Wei & & 0,467 & 0,160 & 0,095 & 0,277 \\
\hline $\mathrm{Val}$ & & 1,130 & 1,378 & 0,806 & 1,742 \\
\hline Deli & & & & & 5,056 \\
\hline
\end{tabular}


Kanthi Pangestuning P, Ridwan Iskandar dan Kasutjianingati, Strategi Peningkatan Kinerja SUPPLY

CHAIN Buah Naga Di Kecamatan Bangorejo Kabupaten Banyuwangi Berdasarkan Proses Inti Scor

Tabel 7. Pengukuran Performansi Supply Chain Perspektif Return

\begin{tabular}{|c|c|c|c|}
\hline \multicolumn{2}{|c|}{ KPI } & $\mathbf{R 1}$ & $\mathbf{R 2}$ \\
\hline \multicolumn{2}{|c|}{ Performance } & 1,500 & 0,000 \\
\hline \multirow{11}{*}{$\underset{\text { 空 }}{\text { 可 }}$} & 10 & $-0,130$ & 0,008 \\
\hline & 9 & 0,005 & 0,012 \\
\hline & 8 & 0,140 & 0,033 \\
\hline & 7 & 1,460 & 0,053 \\
\hline & 6 & 1,625 & 0,073 \\
\hline & 5 & 1,760 & 0,093 \\
\hline & 4 & 1,895 & 0,113 \\
\hline & 3 & 2,030 & 0,133 \\
\hline & 2 & 2,212 & 0,780 \\
\hline & 1 & 2,396 & 0,289 \\
\hline & 0 & 2,580 & 0,500 \\
\hline \multicolumn{2}{|c|}{ Level } & 6,76 & 10 \\
\hline \multicolumn{2}{|c|}{ Weight } & 0,667 & 0,333 \\
\hline \multicolumn{2}{|c|}{ Value } & 4,509 & 3,330 \\
\hline \multicolumn{2}{|c|}{ Return } & \multicolumn{2}{|c|}{7,839} \\
\hline
\end{tabular}

Tabel 8. Pengukuran Performansi Supply Chain Buah Naga

\begin{tabular}{|c|c|c|c|c|}
\hline Perspeldif & $\begin{array}{l}\text { Milai Level } \\
\text { Perspektif }\end{array}$ & KPI & Bobot KPI & $\begin{array}{c}\text { Milgi Letel } \\
\text { KPI }\end{array}$ \\
\hline \multirow{5}{*}{ Plan } & \multirow{5}{*}{4,231} & P! & 0,049 & 2,73 \\
\hline & & $\mathrm{P} 2$ & 0,078 & 2,74 \\
\hline & & $\mathrm{P3}$ & 0,030 & 8,01 \\
\hline & & $\mathrm{P} 4$ & 0,012 & 7,79 \\
\hline & & $\mathrm{DS}$ & 0,018 & 5,20 \\
\hline \multirow{4}{*}{ Sowce } & \multirow{4}{*}{8,007} & S! & 0,068 & 6,78 \\
\hline & & $\$ 2$ & 0,021 & 8,88 \\
\hline & & 53 & 0,036 & 6,60 \\
\hline & & S4 & 0,103 & 8,84 \\
\hline \multirow{7}{*}{ Mabs } & \multirow{7}{*}{5,243} & MI & 0,039 & 6,73 \\
\hline & & $\mathrm{M} 2$ & 0,027 & 8,73 \\
\hline & & $\mathrm{M}^{3}$ & 0,017 & 9,75 \\
\hline & & M4 & 0,011 & 10,00 \\
\hline & & $\mathrm{MS}$ & 0,059 & 8,25 \\
\hline & & $\mathrm{M} 6$ & 0,128 & 3,35 \\
\hline & & M7 & 0,086 & 2,69 \\
\hline \multirow{4}{*}{ Deliver } & \multirow{4}{*}{5,056} & Dl & 0,043 & 2,42 \\
\hline & & $\bar{D} 2$ & 0,015 & 8,01 \\
\hline & & D3 & 0,009 & 8,48 \\
\hline & & D4 & 0,026 & 6,29 \\
\hline Retum & 7,839 & R! & 0,085 & 6,76 \\
\hline
\end{tabular}

Hasil pengukuran pada tingkat perspektif, hanya ada satu perspektif yang berada pada kategori hijau yaitu perspektif source Nilai performansi tertinggi adalah perspektif source sebesar 8,007. Nilai tersebut menunjukkan bahwa performansi supply chain buah naga telah baik dalam penyediaan input produksi sehingga dapat memperlancar proses budidaya buah naga.. Perspektif plan, make, deliver, dan return berada pada kategori kuning.

\section{Rekomendasi Perbaikan}

Berdasarkan hasil analisa menggunakan OMAX dan Traffic Light System terdapat 12 KPI yang masuk dalam kategori merah dan kuning yang dapat dijadikan sebagai akar permasalahan tidak tercapainya performansi KPI guna untuk perbaikan performansi supply chain. Adapun akar permasalahan dan rekomendasi perbaikan disajikan dalam Tabel 9.

Tabel 9. Akar Permasalahan dan Rekomendasi Perbaikan

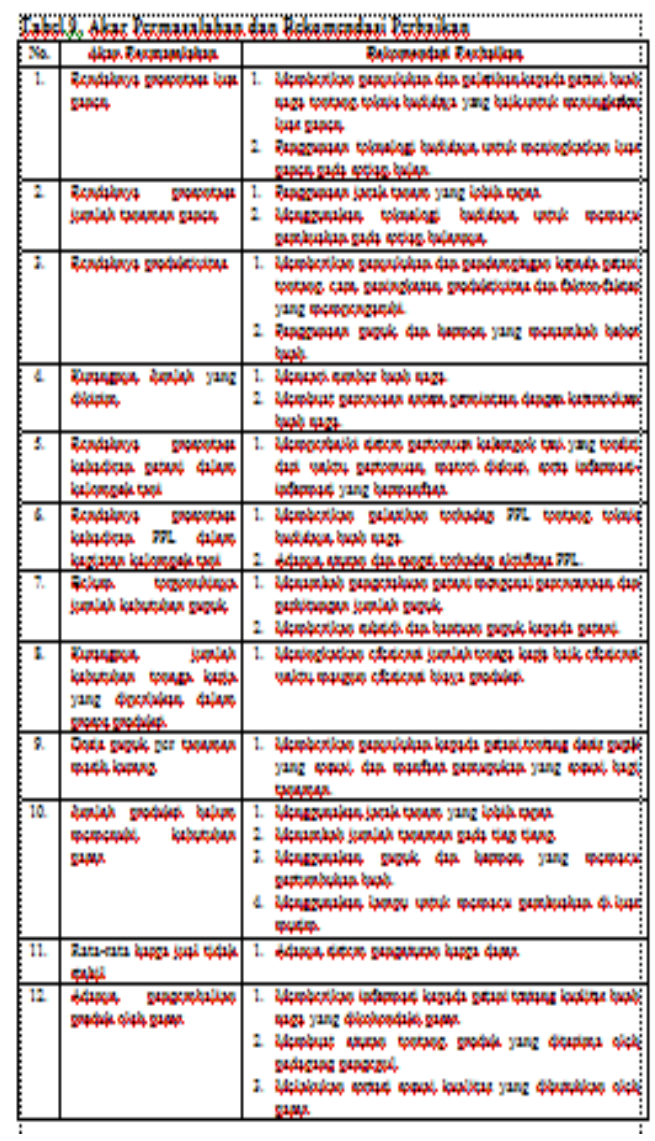




\section{KESIMPULAN}

Berdasarkan hasil penelitian maka dapat diambil kesimpulan sebagaimana berikut :

1. Anggota struktur rantai pasok terdiri dari supplier (kios pertanian, petani, pemerintah, penangkar benih), produsen (petani), distributor (pedagang pengumpul, pedagang besar, pedagang pengecer, pasar tradisional, supermarket).

2. Pengukuran performansi pada SCOR menggunakan lima prespektif sebagai proses inti. Masing-masing perspektif yang digunakan terdiri dari beberapa KPI yaitu plan terdiri dari $5 \mathrm{KPI}$, source terdiri dari $4 \mathrm{KPI}$, make terdiri dari $7 \mathrm{KPI}$, deliver terdiri dari $4 \mathrm{KPI}$, dan return terdiri dari 2 KPI.

3. Pengukuran performansi supply chain menggunakan OMAX terdapat 10 KPI termasuk dalam kategori hijau, 7 KPI termasuk dalam kategori kuning, dan 5 KPI termasuk dalam kategori merah. Nilai total indeks performansi sebesar 5,987 dan berada pada kategori kuning.

4. Rekomendasi perbaikan dilakukan terhadap :

- Prosentase luas panen

- Prosentase jumlah tanaman panen

- Produktivitas

- Jumlah buah naga yang dikirim

- Prosentase kehadiran petani dalam kelompok tani

- Prosentase kehadiran PPL dalam kegiatan kelompok tani

- Pemenuhan kebutuhan pupuk

- Penggunaan tenaga kerja

- Penentuan dosis pupuk

- Jumlah produksi

- Harga jual

- Pengembalian produk

\section{DAFTAR PUSTAKA}

Ahmad NA, Evi Y. 2013. Analisa Pengukuran dan Perbaikan Kinerja Supply Chain di PT. XYZ. Jurnal Teknologi. (6)(2): 179-186.

Astuti R, Machfud, Marimin, Roedhy P, Yandra A. 2010. Kebutuhan Dan Struktur Kelembagaan Rantai Pasok Buah Manggis Studi kasus rantai Pasok di kabupaten Bogor. Jurnal Manajemen Bisnis (3)(1) : $99-115$.

Badan Pusat Statistik. 2014. Banyuwangi Dalam Angka 2014. Banyuwangi. BPS.
Bolstorff, Rosenbaun . 2007. Supply Chain Excellence. United States of America. Amacom.

Buah Naga Banyuwangi Rambah Pasar Nasional. 2015. Industri.Bisnis.com. 19 Januari 2015; $16 \quad$ Mei 2015. http://industri.bisnis.com/read/20150119/9 9/392439/buah-naga-banyuwangi-rambahpasar-nasional

Chopra, S. \& Meindl, P.(2007). Supply Chain Management : Strategy, Planning and Operation. Upper Saddle River, New Jersey. Pearson

Daryanto A. 2009. Peningkatan Daya Saing Peternakan dengan Manajemen Rantai Pasokan. Trobos : April 2009.

Departemen Pertanian. 2014. Data Ekspor-Impor Komoditas Buah Indonesia. Data EksporImpor yang diolah Dirjen Hortikultura. 17 Mei 2014; 5 Mei 2015. http//hortikultura.deptan.go.id.

Heizer J, Barry R. 2008, Manajemen Operasi. Buku 1. Jakarta. Penerbit Salemba.

Heryanto C. 2010. Permintaan Buah-Buahan. JOM Faperta. 5 Mei 2013; 30 April 2015; (2)(1). http://www.bataviase.co.id.

Hualiang L. 2007. The Role Of Guanxi in BuyerSeller Relationship in China: A Survey Vegetable Supply Chain in Jiangsu Province. Netherlands. Wageningen Academic publishers.

Hugo M. 2003. Essential of Supply Chain Management. New Jersey. John Willey and Sons Inc.

James RS, Douglas M.L. 2001. Strategic Logistics Management. Fourthed. McGraw-Hill.

Jaya I. 2010. Morphology and Physiology of Pitaya and it Future Prospect in Indonesia. Mataram. Fakultas Pertanian Universitas Mataram.

Kaltim dan Banyuwangi Menjadi Pusat Buah Naga. 2014. Beritasatu.com. 4 Desember 2014; $\quad 16 \quad$ Mei 2015. http://www.beritasatu.com/kuliner/230639 -kaltim-dan-banyuwangi-jadi-pusatproduksi-buah-naga.html

Kristanto D. 2013. Buah Naga : Pembudidayaan di Pot dan Kebun. Jakarta Penebar Swadaya.

Ling L. 2007. Supply Chain Management : Concept, Techniques and Practices. Enhancing Value Through Collaboration. World Scientific Publishing Co. Pte. Ltd

Mahmudi. 2011. Pengelolaan Pengetahuan Buah Naga. Budidaya dan Pemanfaatannya. 
Kanthi Pangestuning P, Ridwan Iskandar dan Kasutjianingati, Strategi Peningkatan Kinerja SUPPLY

CHAIN Buah Naga Di Kecamatan Bangorejo Kabupaten Banyuwangi Berdasarkan Proses Inti Scor

Jakarta. Lembaga Ilmu Pengetahuan Indonesia.

McCormack. 2008. Supply Chain Maturity and Performance in Brazil. International Journal of Supply Chain Management. (13) (4) : 272-282.

Mulyadi, Setiawan. 2001. Sistem Pengendalian Manajemen. Jakarta. Salemba Empat.

New Zealand Government. 2013. Risk Management Proposal : Fresh Dragon Fruit (Hylocereus spp.) for Consumption From Vietnam. Plant Imports Ministry For Primary Industry. New Zealand. Wellington.

Nurdin R. 2008. Pengukuran dan Analisis Produktivitas Lini Produksi PT. XYZ Dengan Menggunakan Metode Omax. 19 Nopember 2011; 24 Juni 2015. http: //www.stta.ac.id/Jurnal/Omax Sinar Semesta. Pdf.

Paull, Robert E.. 2002. The Dragon Fruit. Departement of Tropical Plant and Soil Sciences. Honolulu. University of Hawaii at Manoa.
Pujawan IN. 2005. Supply Chain Management. Surabaya. Guna Widya.

Santoso I. 2008. Pengembangan Aliansi Strategis dalam Rantai Pasokan Agroindustri Apel. Jurnal Teknologi Pertanian. (10) (8) : 174-180.

Setiawan A, Marimin, Yandra A, Faqih U. 2011. Studi Peningkatan Kinerja Manajemen Rantai Pasok Sayuran Dataran Tinggi di Jawa Barat. Agritech. (31) (1). 60-70.

Sumbayak RET, Yeni S, Rahmi Y. Pengukuran Performansi Supply Chain Berbasis Lima Proses Inti Supply Chain Operation Reference (SCOR) dengan Pendekatan Analytic Network Process (ANP), Studi Kasus : PT. Sang Hyang Seri-Persero Cab. Pasuruan. Malang. Universitas Brawijaya.

Supply-Chain Council Team. 2006. Supply Chain Operation Reference Model Version 8.0. Supply Chain Council, inc.

Tanutomo AS. 2015. Analisa Kinerja Supply Chain Collaboration pada Rumah Buah. Agora. (3) (1) : 293-304.

Winarsih S. 2007. Mengenal dan Membudidayakan Buah Naga. Semarang. Aneka Ilmu. 